\title{
Portfolio Management Simulation as a Learning Tool
}

\section{Gvozdsnovic ${ }^{\star 1}$, Njavro $M^{1}$ and Paradinovic $I^{2}$}

${ }^{1}$ Department of Economics, Zagreb School of Economics and Management, SMC University, Croatia, Switzerland

${ }^{2}$ Department of Economics, KPMG, Zagreb, Croatia, Switzerland

\begin{abstract}
Croatia's financial and capital market is relatively well developed in terms of providing investors and potential investors with access to trading domestically and abroad. The investing infrastructure is by and large in place and is aligned fully with the EU standards. However, most of the active and particularly would-be investors received none or very limited financial and investment education. This result in inferior financial skills and less than adequate asset allocation for the Croatian average investor. A cumulative effect of financially suboptimal literacy of investors has a nation-wide negative impact with less than efficient capital market being only one of its manifestations. With the surge of easily available portfolio management simulations such as Stocktrak, investment and financial concepts are much easier to grasp, understand and implement in the real investment world. Stocktrak simulation proved to be an invaluable supplement in raising financial literacy among finance students and those willing to manage their finances. The paper explores advantages of using the simulation as a supplemental learning curve and demonstrates its importance in dismantling cumulative investing illiteracy in Croatia, which is prerequisite for better asset allocation and the first step towards a more efficient domestic capital market.
\end{abstract}

Keywords: Investments; Portfolio management; Learning tool; Financial skills; Financial literacy; Simulation; Education; Croatia; Southeast Europe

\section{Introduction}

The paper explores advantages of using the simulation as a supplement that boosts the learning curve in investments and demonstrates its importance in dismantling cumulative investment and financial illiteracy in Croatia [1]. Raising awareness of managing personal finances combined with a higher degree of financial and investment literacy among students in Croatia, who are considered soon-to-be investors is prerequisite for better asset allocation and the first step towards a more efficient domestic capital market.

Investors in some of the markets in the South East Europe (SEE) are still lacking easy and efficient access to both local and global capital markets (e.g., Albania, Kosovo). At the same time investors in comparatively more advanced markets (Slovenia, Croatia, Romania, Serbia, Bulgaria) in SEE region have been able to use stock exchange services during the last two decades. This period appears to be insufficient for increasing households' exposure to equity markets in these countries [2]. For illustration purposes - it took several decades for US households to reach exposure that is well above $50 \%$. Namely, exposure to equity investments of US households currently stands at around $68 \%$ up from around $25 \%$ during 1950s.

As a result, asset allocation in countries whose households are insufficiently exposed to equity investments is suboptimal. The reasons for such a low exposure obviously include factors such as low GDP per capita, lack of experience, and financial illiteracy [3]. The focus of this paper is overall importance of financial education with emphasis on being supported by portfolio management simulations such as Stocktrak and resulting financial literacy of the population/students in Croatia where investing infrastructure and laws are aligned with those of other EU markets.

\section{Research Paper}

Most of the Croatian active investors and particularly would-be investors received none or very limited formal financial/investment education. This obviously results in inferior financial skills and less than adequate asset allocation for the Croatian average investor [4]. A cumulative effect of financially less than literate Croatian investors results in a nation-wide negative impact with inefficient capital market being only one of its manifestations.

\section{Significance of the Research}

The paper offers findings based on the data and experience gathered over the last ten years of using a portfolio management simulation as a teaching tool at undergraduate level. The significance of the paper resides in its results that can be used by a wide range of education analysts, business school officials, and government officials who deal with envisioning and steering the higher education curricula that pertains to the field of finance.

Furthermore, the paper can serve as a stepping stone for future research to be conducted and which will be based on the findings and results of this one. Some of the research questions that could be researched while based on this paper's results include deciphering the relationship between the Croatian student body and its exposure to the capital markets, understanding average risk aversion of Croatian students in relation to equity investments, and portraying the students' current risk-return expectations.

*Corresponding author: Gvozdsnovic I, Department of Economics, Zagreb School of Economics and Management, SMC University, Croatia, Switzerland, Tel: +41(0)415608057; E-mail: igor.gvozdanovic@swissmc.ch

Received May 13, 2016; Accepted September 21, 2016; Published September 26, 2016

Citation: Gvozdsnovic I, Njavro M, Paradinovic I (2016) Portfolio Management Simulation as a Learning Tool. J Glob Econ 4: 214. doi: 10.4172/23754389.1000214

Copyright: $\odot 2016$ Gvozdsnovic I, et al. This is an open-access article distributed under the terms of the Creative Commons Attribution License, which permits unrestricted use, distribution, and reproduction in any medium, provided the original author and source are credited. 


\section{Steeping the Learning Curve by the Simulation-briefly on how it Works}

Each student manages their own portfolio, which is denominated in any hard currency or their mixture - depending on the students' preferred currency exposure. Students are "given" 1 million USD which they can invest in any of many assets via major stock exchanges in the world. The simulation tracks the student's portfolio Figure 1 on a daily basis. Students benefit from real-time, streaming platforms that feature global equities, bonds, options, futures, commodities and more. Students have also their private contests for their classes and at the same time compete with appropriate benchmark indices by selecting common trading dates, initial cash balance, and many other trading parameters.

Over the course of fifteen weeks, students practice trading strategies, compete with the chosen benchmark indices while handling day-to-day transactions and posting real-time bid/ask order executions via 50+ global exchanges. Students learn to use a full range of order types including: Market, Limit, Stop, Trailing Stop \$, Trailing Stop \%. An example of a Portfolio Summary is depicted in the Figure 2 below while Figure 3 provides a graphical discrepancy between the portfolio performance and its benchmark index. These are only some of the many features that the simulation provides to its users.

\section{Research Methodology}

The research methodology used in the paper is qualitative. Over the last ten years the undergraduate students who were taking Investments course would fill out questionnaires with questions on basics of investments and finance prior and after using the portfolio management simulation [1]. The discrepancy in understanding concepts of investing and issues pertaining to optimal asset allocation shows the impact of using the portfolio management simulation for educational purposes.

Presented below are merely some of the questions that the students answered prior and after having participated at the Investments course in which they used Stocktrak portfolio management simulation for fifteen consecutive weeks.

1. How would you rate the degree of your understanding and knowledge with respect to equity instruments?

2. What is the difference in your knowledge and understanding of equity markets and importance of personal financial and investment discipline prior and after using the portfolio management simulation for the last fifteen weeks?

3. According to your preferred risk-return expectations and risk aversion profile, what kind of asset allocation you regard as an optimal one?

\section{Results and Conclusion}

With the surge of easily available portfolio management simulations such as Stocktrak, investment and financial concepts are much easier to grasp, understand and implement in the real investment world. Portfolio management simulations provide a riskfree and hands-on approach to acquiring investment knowledge and portfolio management experience. The Stocktrak simulation appears to represent an invaluable supplement in raising financial literacy among finance students and more broadly among those willing to manage their finances utilizing the capital market infrastructure. As a result, the students who actively used such an educational tool can be expected to tap the investment arena much sooner than their peers who have not been exposed to a similar education. This in turn translates into a longer investment horizon for the former ones with arguably more meaningful investing experience and better opportunity for securing their old age income. Bringing this knowledge and experience to the national level of rating financial literacy, it is clear that those who used simulations have more realistic risk-return expectations as well as somewhat better aligned risk aversion, i.e., those students with experience tend to be less

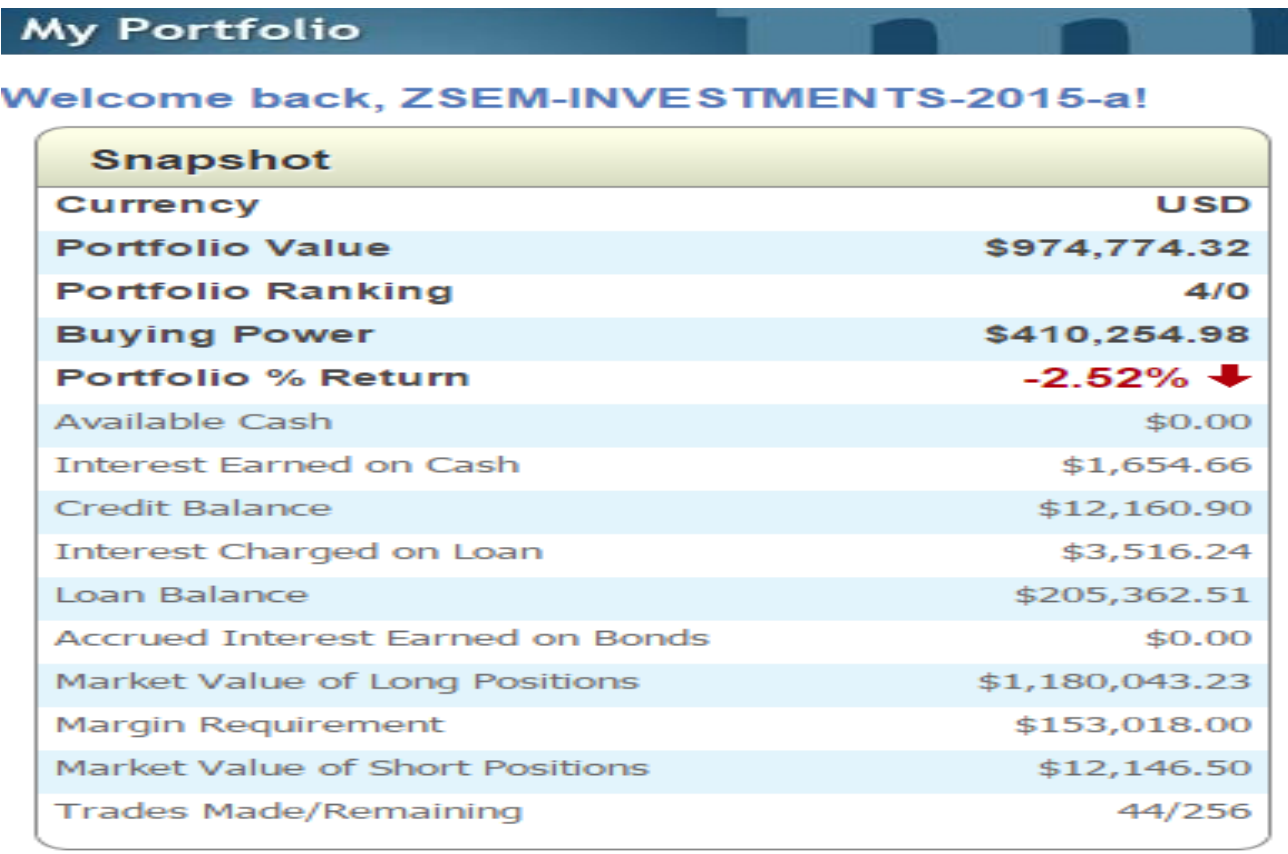

Figure 1: The simulation tracks the student's portfolio on a daily basis. 
Citation: Gvozdsnovic I, Njavro M, Paradinovic I (2016) Portfolio Management Simulation as a Learning Tool. J Glob Econ 4: 214. doi: 10.4172/23754389.1000214

\section{Portfolio Summary}

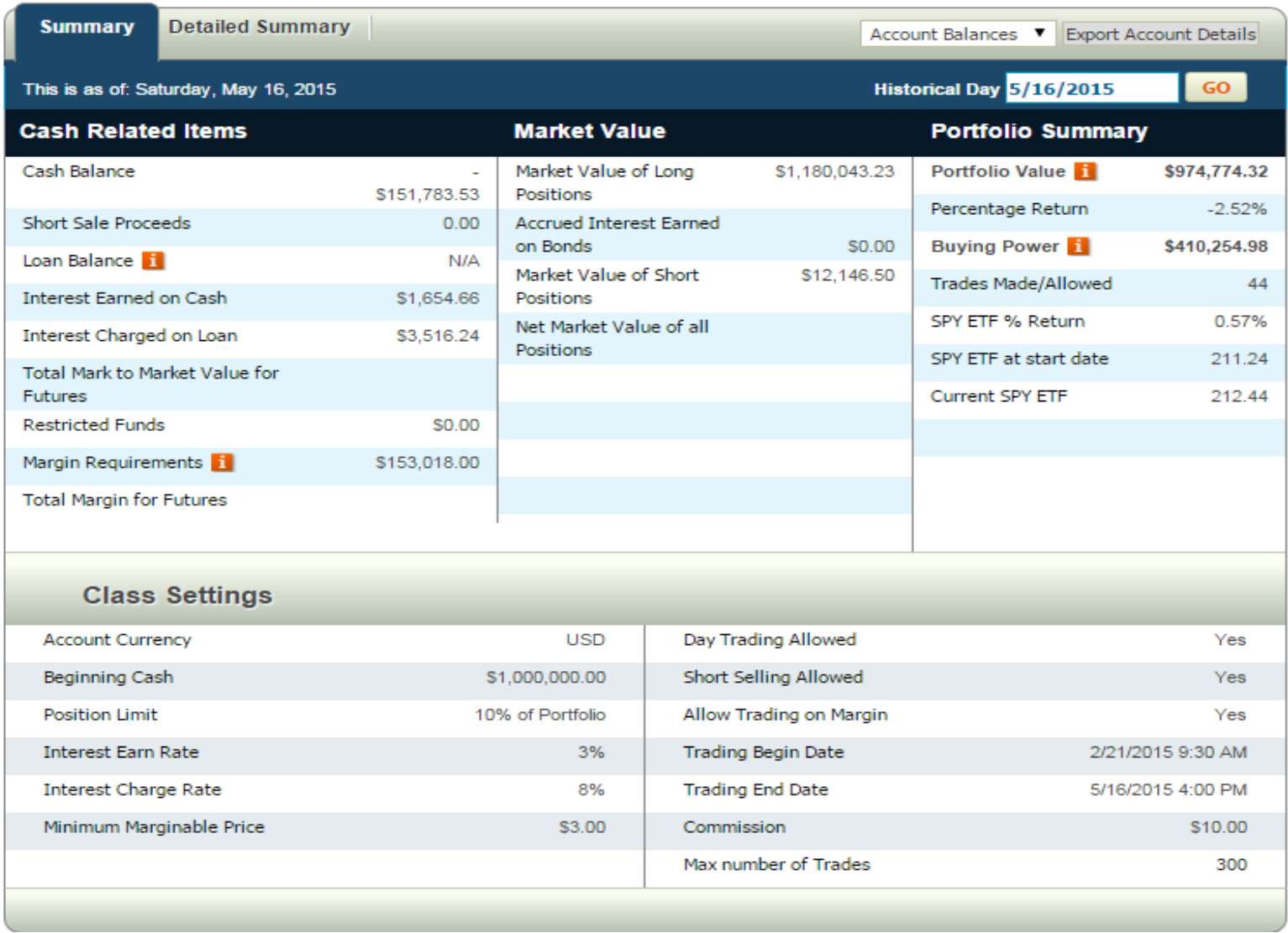

Figure 2: Portfolio summary

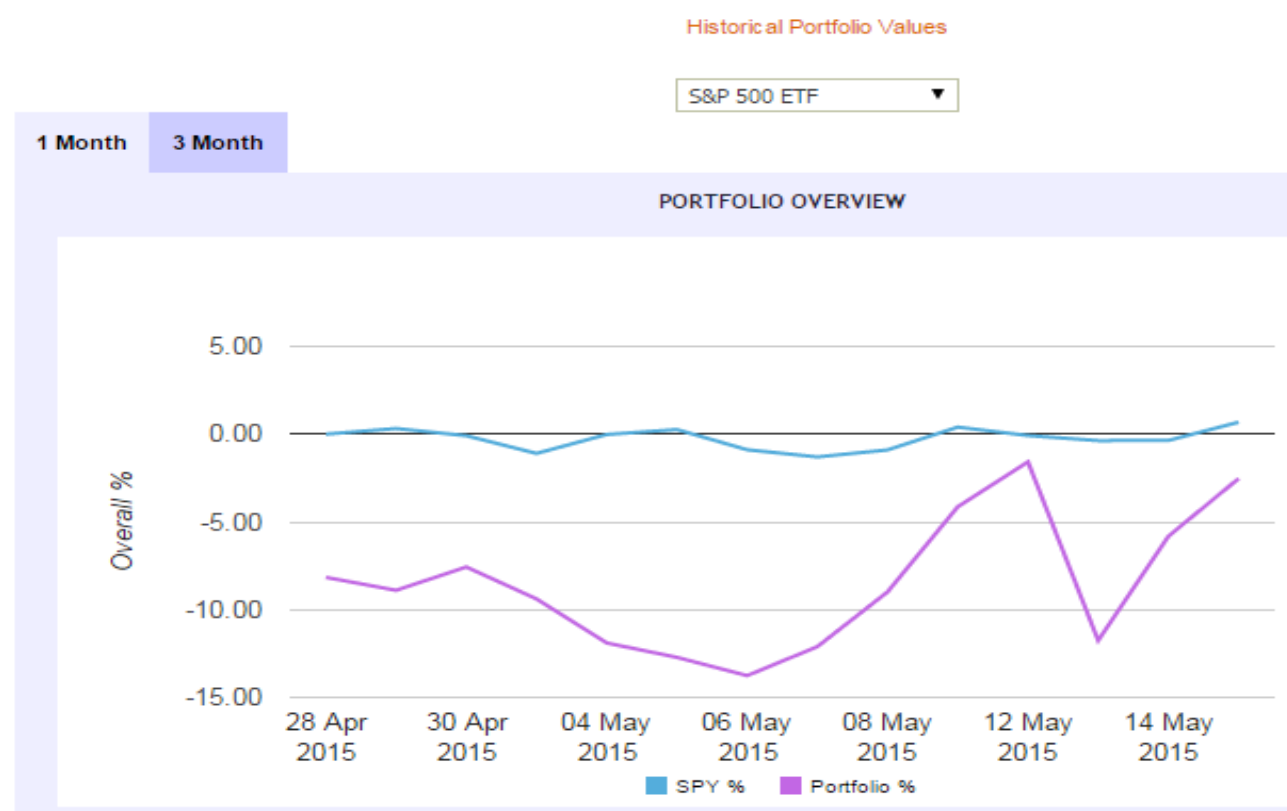

Figure 3: A graphical discrepancy between the portfolio performance and its benchmark index. 
Citation: Gvozdsnovic I, Njavro M, Paradinovic I (2016) Portfolio Management Simulation as a Learning Tool. J Glob Econ 4: 214. doi: 10.4172/23754389.1000214

Page 4 of 4

risk averse in their young age while becoming increasingly risk averse as they approach their golden age. This again translates into better asset allocation for individuals and if the nation is composed of individuals who understand peculiarities of equity and fixed income markets (that can be observed by investing via simulation at an early stage in life), the asset allocation is theoretically approaching its optimal point also on a national level.

\section{References}

1. Thomas PA (2004) A Modern Approach to Graham and Dodd Investing. John Wiley \& Sons, Inc., USA.

2. Corporate Policy (2007) Calculating Debt-to-Capital Ratio.

3. Karlof B, Lovingsson FH (2005) The A-Z of Management Concepts and Models Thorogood Publishing, London.

4. Piotroski J (2000) Value Investing: The Use of Historical Financial Statement Information to Separate Winners from Losers. J Account Res 38: 1-41. 